\title{
HISTOPATHOLOGICAL AND IMMUNOHISTOCHEMICAL STUDIES OF THE RAT DORSOLATERAL PROSTATE EFFECTS OF TESTOSTERONE AND
TESTOSTERONE PLUS ESTROGEN
}

\author{
Masanori Murakoshi, Rie Inada, Masashi Tagawa, and Minoru Suzuki \\ Safety Research Department, Teikoku Hormone Mfg. Co., Ltd
}

Atsushi Mizokami

Department of Molecular Cell Biology, University of Occupational and Environmental Health

Keiichi Watanabe

Department of Pathology, Tokai University, School of Medicine

\begin{abstract}
The effects of testosterone and $17 \boldsymbol{\beta}$-estradiol $\left(\mathrm{E}_{2}\right)$ on the dorsolateral prostate of castrated rats were investigated by histopathological and immunohistochemical procedures. Male Sprage-Dawley rats were divided into four experimental groups. Group 1 consisted of intact controls. The other animals were castrated. In group 2, rats were sacrificed 2 days after castration. The castrated animals were treated for 6 weeks with 1 ) testosterone $1 \mathrm{mg} /$ head (Group 3) and 2) testosterone $1 \mathrm{mg} /$ head plus $E_{2}$ $10 \mu \mathrm{g} /$ head (Group 4). A significant increase in the dorsolateral prostatic weight occurred after 6 weeks treatment with testosterone plus $\mathrm{E}_{2}$ (Group 4). Histopathologically, glandular hyperplasia with fibromuscular stromal proliferation was clearly observed, and the number of bromo-deoxyuridine (BrdU)positive cells showed a significant increase over that induced by testosterone alone. Immunohistochemical localization of glutathione peroxidase (GSH-PO) which effectively reduces the lipid peroxides, was clearly observed in the glandular epithelial cells of the dorsolateral prostate following testosterone alone or testosterone plus $\mathrm{E}_{2}$-treatment. Therefore, it appeared that GSH-PO protein synthesis in the glandular epithelium of the dorsolateral prostate can be enhanced (induced?) by sex hormones such as testosterone and $\mathrm{E}_{2}$. In the dorsolateral prostate of intact rats, positive staining for androgen receptor (AR) was observed in nuclei of the glandular epithelial cells. In addition, immunodetectable AR decreased within 2 days after castration, but returned to intact levels after administration of testosterone. These findings agree with previous work on the ventral prostate. Furthermore, in group 4, AR was also detected in the nuclei of the proliferated stromal fibro-muscular cells. It is concluded that immunohistochemical analysis, using GSH-PO and AR, may be a useful method for predication of the effects of androgen action on the rat prostate. (J Toxicol Pathol $7: 387 \sim 395,1994$ )
\end{abstract}

Key words: Testosterone, 17 $\beta$-estradiol, Prostatic hyperplasia model, Glutathione-peroxidase (GSHPO), Androgen receptor

村越正典 稲田理恵 田川正志 鈴木 稔 拝上 敦 渡辺慶一

Accepted for publication: April 30, 1994

Mailing address: Masanori Murakoshi, Safety Research

Department, Teikoku Hormone Mfg. Co., Ltd., 1604

Shimosakunobe, Takatsu-ku, Kawasaki 213, Japan.

\section{Introduction}

In a previous report ${ }^{1}$, it was shown that glandular hyperplasia of the ventral prostate developed in castrated rats after combined treatment with testosterone and $17 \beta$-estradiol. It is generally accepted that estrogens play a critical role in the etiology of canine and human benign prostatic 
hyperplasia ${ }^{2-5}$.

The dorsolateral prostate of the rat has been shown to be particularly to estrogen ${ }^{6-8}$. Specific receptor for estrogen has demonstrated in the dorsolateral prostate ${ }^{9}$. Therefore, it should be a good model for human prostate, since besides androgens, estrogens are supposed to have an important role in its physiology and pathology4.

The purpose of the present study was to examine the effects of testosterone, and testosterone plus $17 \beta$-estradiol, on the castrated rat dorsolateral prostate. In addition, an analytical examination for cell proliferation activity, using 5-bromo-deoxyuridine (BrdU)-positive cell ratio and an attempt to observe immunocytochemical localization of androgen receptor (AR) and glutathione-peroxidase (GSH-PO), which effectively reduces the lipid peroxides, were also investigated.

\section{Materials and Methods}

\section{Animals}

Male Sprague-Dawley rats were purchased from Charles River Japan Inc. (Atsugi, Japan) at the age of five weeks. The animals were kept in a barrier-maintained room, which was maintained at a temperature of $22 \pm 2^{\circ} \mathrm{C}$ and humidity of $55 \pm$ 15\%. The room was ventilated twenty-one times per hour and provided with $12 \mathrm{hr}$ of light (from $800 \mathrm{hr}$ to $2,000 \mathrm{hr}$ ). The animals were housed individually in plastic cages (CLEA Japan, Inc.). Solid food (CE-2, CLEA Japan, Inc.) and tap water were available to all animals ad libitum. Then one week was allowed for the adjustment of animals to laboratory conditions.

\section{Experiments}

Group 1 consisted of 5 untreated controls. In group 2, 5 rats were sacrificed 2 days after castration. In group 3,5 rats were treated subcutaneously $1 \mathrm{mg} /$ head of testosterone (Sigma Chemical Co., St. Louis, MO. U.S.A.) daily for 6 weeks after 2 days of castration. In group 4, 5 rats were treated subcutaneously $1 \mathrm{mg} /$ head of testosterone plus $10 \mu \mathrm{g} /$ head of $17 \beta$-estradiol $\left(E_{2}\right.$, Teikoku Hormone, Mfg. Co. Ltd, Kawasaki) daily for 6 weeks after 2 days of castration. Testos- treone was dissolved in dimethylsulfoxide (Wako Pure Chemical Industries, Osaka) and $E_{2}$ was dissolved in triolein (Sigma Chemical Co., St. Louis, MO, U.S.A.). One hour prior to sacrifice, animals were given an intraperitoneal injection of 5-bromo-2-deoxyuridine (BrdU, Sigma Chemical Co., St. Louis, MO, U.S.A.), at a dose of $100 \mathrm{mg}$ / $\mathrm{kg}$ body weight. Each rat was killed by decapitation, and the dorsolateral prostate was removed.

\section{Organ weight}

The weight of the dorsolateral prostates was recorded (absolute weight). Weight relative to body weight (relative weight) was calculated.

\section{Histopathological examination}

The dorsolateral prostates were fixed in $0.1 \mathrm{M}$ phosphate-buffered $10 \%$ formalin, embedded in paraffin, mounted and stained with hematoxylin and eosin (HE).

\section{Immunohistochemical staining}

\section{1) $\operatorname{BrdU}$}

Formalin fixed and paraffin sections were used. Sections $(4 \mu \mathrm{m})$ were cut, deparaffinized with xylene and rinsed thoroughly with ethanol. The sections were then placed in absolute methanol containing $0.3 \%$ hydrogen peroxide for $30 \mathrm{~min}$ at room temperature in inactivate endogenous peroxidase activity. Sections were washed twice in $0.01 \mathrm{M}$ phosphate-buffered saline (PBS), $\mathrm{pH}$ 7.4, $5 \mathrm{~min}$ per wash. Thereafter, sections were immersed in $2 \mathrm{~N} \mathrm{HCl}$ at $25^{\circ} \mathrm{C}$ for 20 min denature the DNA. To neutralize the $\mathrm{HCl}$, the sections were rinsed in $0.1 \mathrm{M}$ borate buffer, $\mathrm{pH}$ 7.6. After

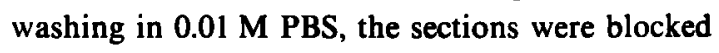
with $5 \%$ normal goat serum for $30 \mathrm{~min}$, then incubated for $2 \mathrm{hr}$ with 1:50 mouse monoclonal anti-BrdU antibody (Becton Dickinson immunocytometry Systems, San Jose, CA). After washing in $0.01 \mathrm{M}$ PBS, the sections were covered with biotin-conjugated goat anti-mouse IgG for 1 $\mathrm{hr}$, washed and then incubated with streptavidinbiotin complex (Histofine SAB-PO (M) Kit, Nichirei, Tokyo) for $1 \mathrm{hr}$. After washing in $0.01 \mathrm{M}$ PBS, the sections were incubated in GrahamKarnovsky's reaction medium ${ }^{10}$ which contained 3, 3'-diaminobenzidine-tetra-hydrochloride (DAB, 
Wako Pure Chemical Industries, Osaka) and $0.005 \%$ hydrogen peroxide in $0.05 \mathrm{M}$ Tris $-\mathrm{HCl}$ buffer, $\mathrm{pH} 7.6$, for $10 \mathrm{~min}$ at room temperature. Then the sections were counter-stained for nuclei with hematoxylin. As an immunologically negative control, 1:50 diluted nonimmune mouse serum was used. In addition, the BrdU-positive cell ratio (\%) was calculated as the positive cell number in one acinus/total cell number in the acinus $\times 100$.

\section{2) $\mathrm{GSH}-\mathrm{PO}$}

The dorsolateral prostates were fixed in periodate-lysine-4\% paraformaldehyde solution (4\% PLP) ${ }^{11}$ for $6 \mathrm{hr}$ at $4^{\circ} \mathrm{C}$ under constant agitation. The fixed tissues were then washed in 0.01 M PBS, containing sucrose from 10 to eventually $20 \%$ overnight at $4^{\circ} \mathrm{C}$. Subsequently, $6 \mu \mathrm{m}$ frozen sections were prepared from the washed tissues in a cryostat, and were placed on albumin coated glass slides. The sections were washed in 0.01 M PBS and then were stained by Nakane's direct peroxidase-labeled antibody method with anti-GSHPO IgG Fab fragment ${ }^{12}$. For light microscopic observations of GSH-PO, $6 \mu \mathrm{m}$ frozen sections were incubated with the antibody labeled with horseradish peroxidase (Sigma Chemical Co., St, Louis, MO, U.S.A.) for $1 \mathrm{hr}$. After the incubation was completed, the immuno-peroxidase staining was performed as described above.

3) $A R$

Fresh dorsolateral prostates were frozen in dry-ice cooled ethanol. $6 \mu \mathrm{m}$ thickness of frozen sections were prepared in a cryostat and attached to albumin-coated glass slides. The sections were fixed for $10 \mathrm{~min}$ at $4^{\circ} \mathrm{C}$ in Zamboni's fixative ${ }^{13}$. After washing with $0.01 \mathrm{M}$ PBS containing $20 \%$ sucrose, the sections were soaked in absolute methanol containing $0.3 \%$ hydrogen peroxide for $30 \mathrm{~min}$ at room temperature in inactivate endogenous peroxidase activity. After washing in $0.01 \mathrm{M}$ PBS, the sections were incubated overnight at $4^{\circ} \mathrm{C}$ with $\mathrm{NH} 27$, a rabbit polyclonal anti-AR antibody $(1: 1000)^{14}$. After washing in $0.01 \mathrm{M}$ PBS, the sections were covered with biotin-conjugated goat anti-rabbit IgG for $1 \mathrm{hr}$, washed and then incubated with streptavidin-biotin complex (Histofine SAB-PO (R) Kit, Nichirei, Tokyo) for $1 \mathrm{hr}$. After washing in $0.01 \mathrm{M}$ PBS, the immunoperoxidase staining was performed as described above.

\section{Results}

\section{Prostatic weights}

The dorsolateral prostatic weight is shown in Table 1. Those of the intact and castrated groups were comparable. Statistically significant increase was noted in the absolute $(p<0.05)$ and relative $(p<0.01)$ weight of the dorsolateral prostate of the castrated rats treated with testosterone plus $E_{2}$.

2. Histopathological and immunocytochemical findings

\section{Group 1 (Intact control)}

Epithelial cells lining the dorsolateral prostate were columnar and the nuclei were located mainly in basal portion of the cells (Fig. 1A). A few BrdU-positive nuclei were observed in the glandular epithelial cells (Table 1). In the glandular epithelial cells, immunohistochemical localization of GSH-PO was weak or negative (Fig 2A). AR

Table 1. Influence of Testosterone $(T)$ or $T$ Plus $17 \beta$-estradiol $\left(E_{2}\right)$ on the Weight of Rat Dorsolateral Prostate and BrdU-positive Cell Ratio

\begin{tabular}{|c|c|c|c|c|c|c|}
\hline \multirow{2}{*}{ Group } & \multirow{2}{*}{ Preparation } & \multirow{2}{*}{$\mathrm{n}$} & \multirow{2}{*}{ Treatment } & \multicolumn{2}{|c|}{ Prostatic weight (mg) } & \multirow{2}{*}{ BrdU-positive cell ratio (\%) } \\
\hline & & & & Absolute & Relative & \\
\hline 1 & Intact control & 5 & - & $298 \pm 48.3$ & $68 \pm 12.1$ & $0.31 \pm 0.12$ \\
\hline 2 & Castrated & 5 & - & $285 \pm 31.5$ & $61 \pm 9.8$ & $0.08 \pm 0.01$ \\
\hline 3 & Castrated & 5 & $\mathbf{T}$ & $399 \pm 98.6$ & $88 \pm 42.3$ & $1.35 \pm 0.81$ \\
\hline 4 & Castrated & 5 & $T+E_{2}$ & $593 \pm 81.5^{*}$ & $108 \pm 22.3^{* *}$ & $3.94 \pm 0.23^{* *}$ \\
\hline
\end{tabular}

Values are mean \pm S.D.

*, $\mathrm{P}<0.05$ vs. intact control (Dunnett's multiple comparison test).

**, $\mathrm{P}<0.01$ vs. intact control (Dunnett's multiple comparison test). 
was localized exclusively in the nuclei of the epithelial cells (Fig. 3A). No immunostaining was observed in the nuclei when the section were incubated with preimmune serum.

\section{Group 2 (Castration)}

Two days after castration, the height of glandular epithelial cells was slightly reduced (Fig. 1B). BrdU-positive nuclei in the glandular epithelial cells were rarely seen (Table 1). Both GSHPO (Fig. 2B) and AR (Fig. 3B) were negative or very weak in the glandular epithelial cells.

\section{Group 3 (Castration + Testosterone)}

The glandular epithelial cells were of a high columnar shape (Fig. 1C). The number of BrdUpositive nuclei was increased compared with intact control (Table 1). GSH-PO was stained in those glandular epithelial cells (Fig. 2C). In addition, nuclear immunostaining of $\mathrm{AR}$ in the glandular epithelial cells was also observed (Fig. $3 \mathrm{C}$ ).

Group 4 (Castration + Testosterone $+E_{2}$ )

The glandular epithelial cells were high, columnar, and showed an increased number of papillary projections extending into acini (Fig. 1D). In addition, the epithelium showed a highly secretory appearance. Interacinar stroma was also proliferated. The number of BrdU-positive nuclei was greatly increased compared to the other experimental groups (Table 1). Immunohistochemical localization of GSH-PO staining was stronger than that of Group 3. In addition, the glandular epithelial cells showed uniformly intense nuclear immunostaining for AR (Fig. 3D). Furthermore, AR was also detected in the nuclei of the stromal fibro-muscular cells.

\section{Discussion}

In the present study, the weight of the dorsolateral prostate was markedly increased by testosterone plus $E_{2}$ to the castrated rats. In addition, it was seen that the castration-induced decrease in the number of BrdU-positive cells was reversed by testosterone. The stimulatory effects of testosterone were strongly potentiated by the addition of $E_{2}$, resulting in the highest BrdUpositive cell ratio. Histologically, glandular hyperplasia was clearly seen in this group. It is known that $E_{2}$ alone induces glandular atrophy of the prostate in normal and castrated animals ${ }^{5,15}$. The suppressive effects of $E_{2}$ on the male genital organs have been attributed not only to gonadotropin suppression but also to the direct effect of $E_{2}$ on the gonads and their accessories $^{15-17}$. On the contrary, it is a well documented fact that $E_{2}$ exerts a synergistic effect with androgen in promoting prostatic growth in the castrated dog or rat, a fact of considerable importance in understanding the pathogenesis of prostatic hyperplasia. Fibro-muscular stromal proliferation was also seen in the group of rats receiving the combination treatment. This feature might be explained by the action of $E_{2}$, since growth of stromal tissue following estrogen administration has been demonstrated in the prostate of non-human primates and dogs ${ }^{18}$. Furthermore, Rohr et al. ${ }^{19}$ demonstrated that treatment of castrated dog with $E_{2}$ resulted in activation of the stromal tissue in association with smooth muscle cells.

Previously, we demonstrated that the intensity of GSH-PO staining in the glandular epithelial cells of the ventral prostate decreased following castration, and could be reversed by testosteroneadministration to the castrated rats ${ }^{1}$. We therefore postulated that prostatic GSH-PO may be testosterone-dependent. In the present study, we found that immunohistochemical staining of GSHPO in the glandular epithelium of the dorsolateral prostate was clearly responsive to testosterone alone or in combination with $E_{2}$. Therefore, it seems likely that GSH-PO protein synthesis in the glandular epithelium of the dorsolateral prostate can be enhanced (induced?) by sex hormones such as testosterone and $E_{2}$. In fact, the significant increase of GSH-PO protein triggered by lipid peroxides has also been demonstrated in an experimental system of inactivation and reactivation of the arachidonate cascade in rat peritoneal macrophages ${ }^{20,21}$. These findings indicated that increased levels of lipid peroxides (or peroxidation) enhanced the expression of GSH-PO, op, in other words, the decrease of lipid peroxides might reduce the expression. We suggest that lipid peroxidation was increased in the dorsolateral prostate by the testosterone alone, or testosterone plus $E_{2}$-treatment. Further work in this area is 


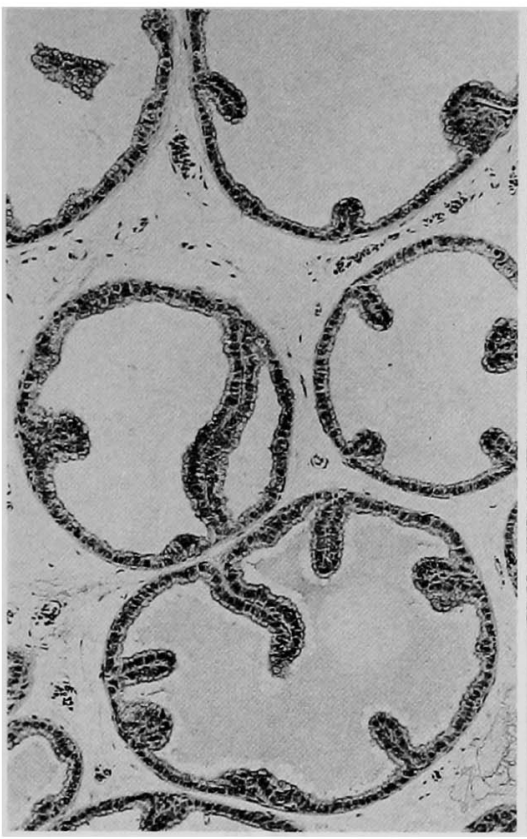

Fig. 1A

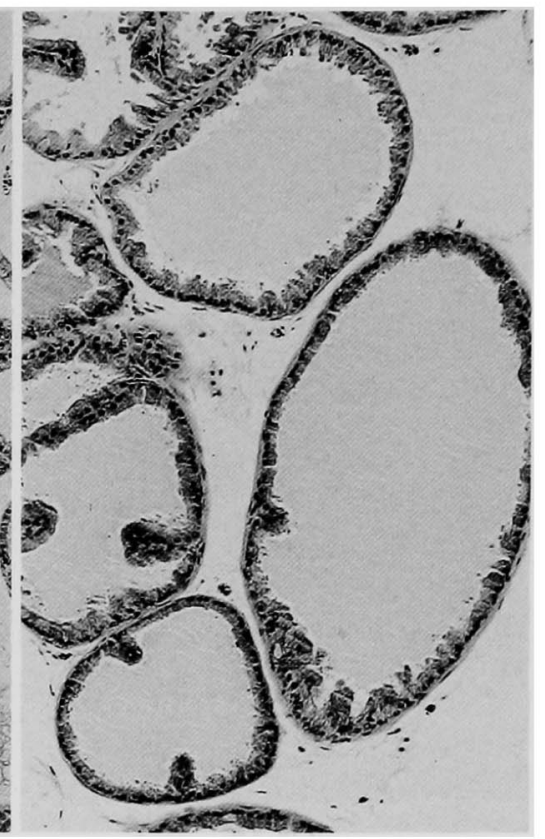

Fig. 1B

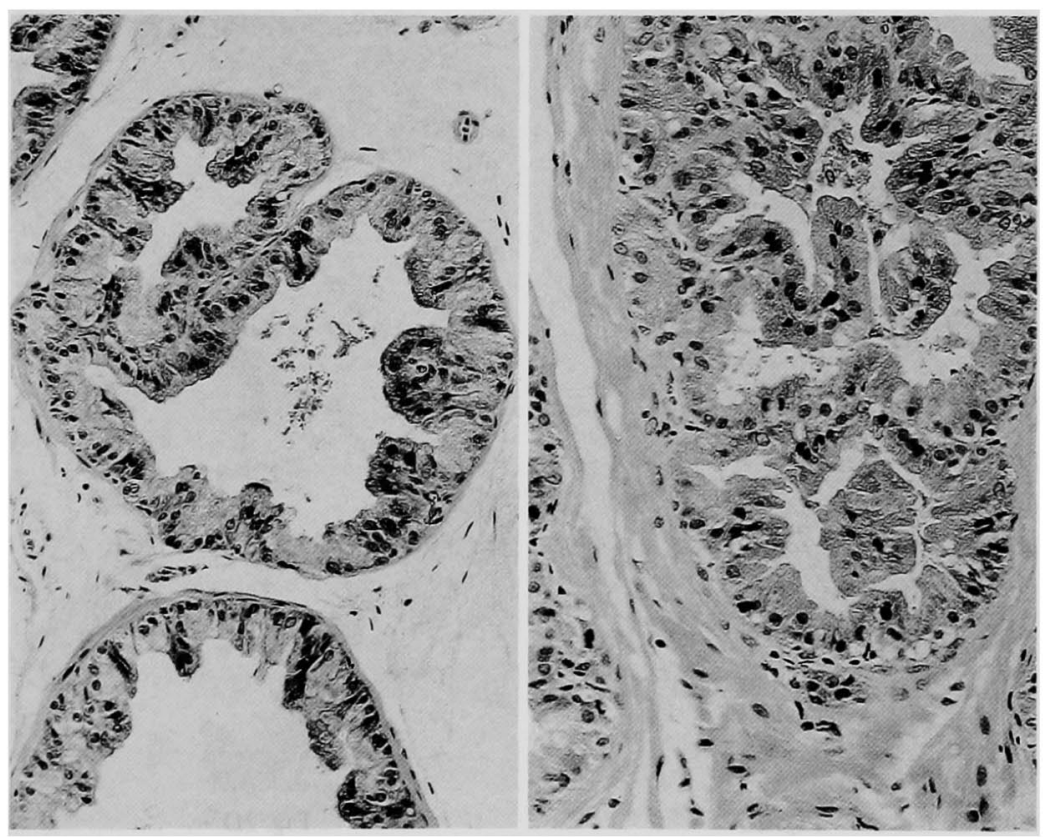

Fig. 1C

Fig. 1D

Fig. 1. A : Dorsolateral (DL) prostate of intact rat. B : DL prostate of castrated rat. The glandular epithelial cells are atrophic. C: DL prostate of castrated rat following treatment with testosterone. The glandular epithelial cells are of a highly columnar shape. D : DL prostate of castrated rat following treatment with combined testosterone and $\mathbf{E}_{2}$. Glandular hyperplasia with stromal proliferation is clearly observed.

HE $\times 100$ (A, B, C, D). 


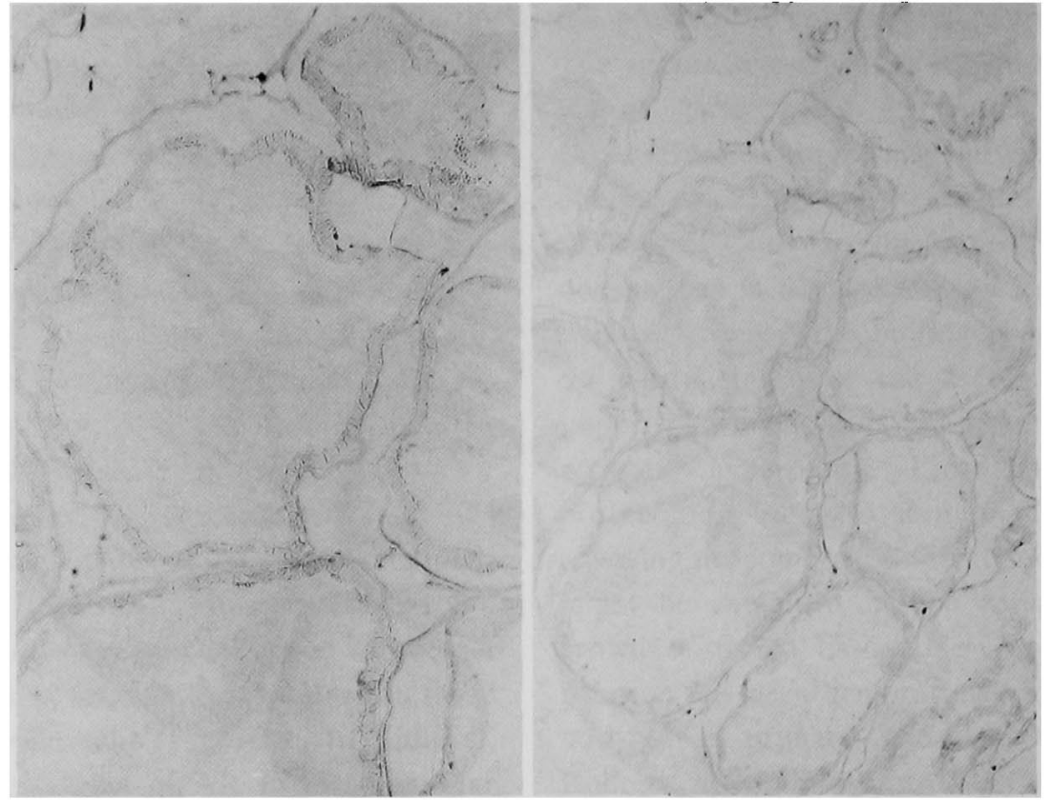

Fig. 2A

Fig. 2B

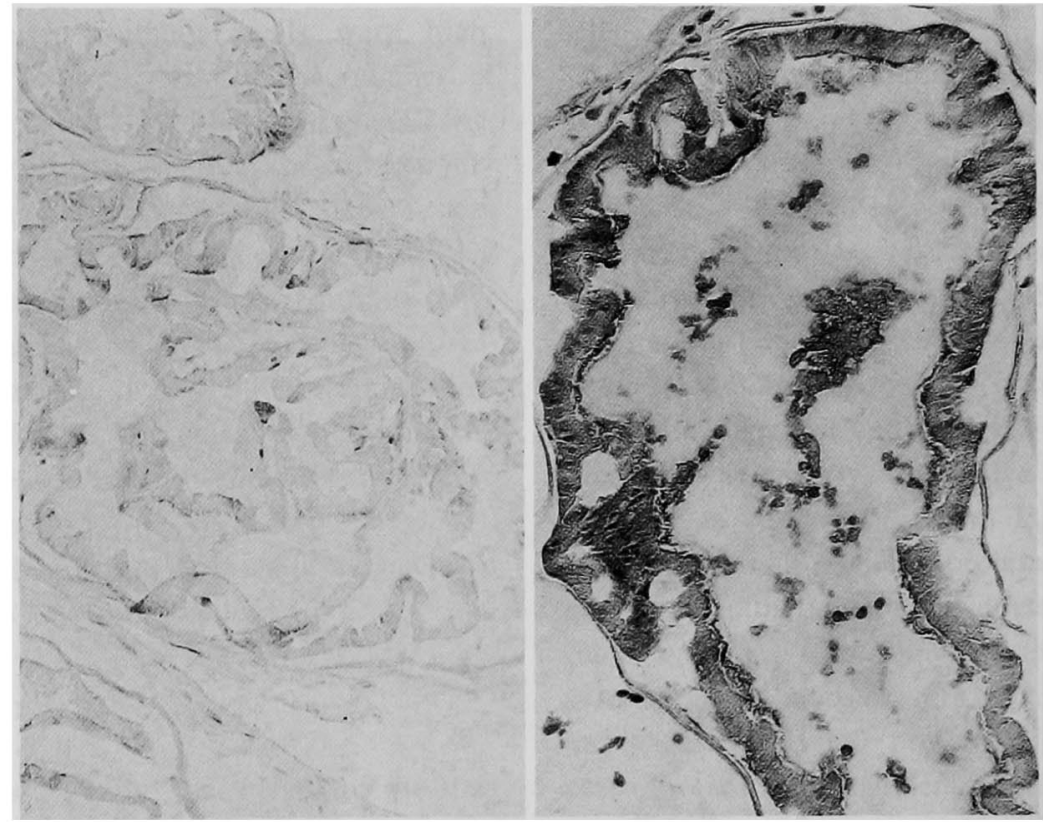

Fig. 2C

Fig. 2D

Fig. 2. A : Dorsolateral (DL) prostate of intact rat. B : DL prostate of castrated rat. C: DL prostate of castrated rat following treatment with testosterone. GSH-PO in the glandular epithelial cells clearly detected. D : DL prostate of castrated rat following treatment with combined testosterone and $E_{2}$. The intensity of GSH-PO staining is remarkably increased.

Peroxidase-labeled antibody method, $\times 90$ (A, B, C, D). 


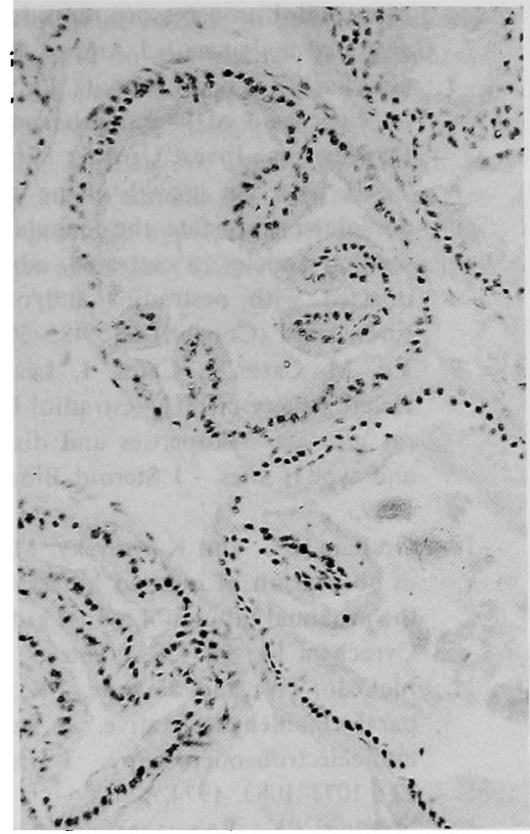

Fig. 3A
Fig. 3B

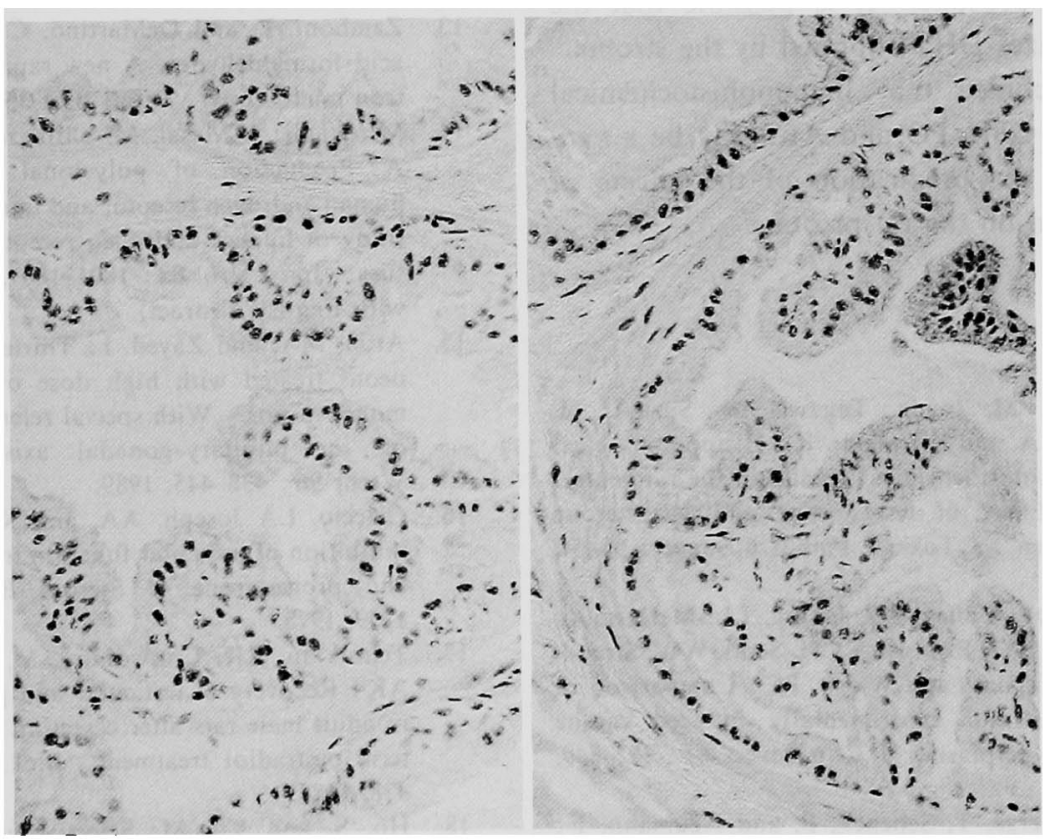

Fig. 3C

Fig. 3D

Fig. 3. A : Dorsolateral (DL) prostate of intact rat. AR is localized exclusively in the nuclei of the glandular epithelial cells. B : DL prostate of castrated rat. AR is negative in the glandular epithelial cells. C : DL prostate of castrated rat following treatment with testosterone. AR is clearly noted in the nuclei of the glandular epithelial cells. D: DL prostate of castrated rat following treatment with combined testosterone and $E_{2}$. AR is localized in the nuclei of the glandular epithelial cells.

Furthermore, AR is also detected in the nuclei of the stromal cells.

Avidin-biotin-peroxidase-complex method, $\times 100$ (A, B, C, D). 
now in progress in our laboratory.

A rabbit polyclonal antibody referred as NH27 was raised against human $\mathrm{AR}^{14}$. The specificity of the antibody in immunohistochemical reactions has been described elsewhere ${ }^{1,22,23}$. In the present work, we found that immunodetectable AR was decreased 2 days after castration, and that it was clearly recovered testosterone-administration to the castrated rats. These findings are in agreement with the results of previous work on the ventral prostate. AR was also detected in the nuclei of the proliferated stromal fibro-muscular cells. Human prostate epithelial cells in benign prostatic hyperplasia showed uniformly intense nuclear staining for $\mathrm{AR}^{24}$. Furthermore, intense AR staining has been observed in stromal cells of fibro-muscular hyperplasia ${ }^{24}$. The intense staining of AR in the epithelium is also in contrast with the abundance of $5 \alpha$-reductase in the stroma, which coverts testosterone into dihydrotestosterone (DHT) in the prostate. It is possible that the epithelium utilizes DHT supplied by the stroma.

It is concluded that immunohistochemical analysis, using GSH-PO and AR, may be a very useful method for predication of the effects of androgen action on the rat prostate.

\section{References}

1. Murakoshi, M, Inada, Tagawa, $\mathbf{M}$, Suzuki, $\mathbf{M}$, Mizokami, A, and Watanabe, $\mathrm{K}$ : Histopathological and immunohistochemical studies in the rat ventral prostate. Effect of testosterone and testosterone plus estrogen. J Toxicol Pathol 6(Suppl) : 55-64, 1993.

2. DeKlerk, DP, Coffey, DS, Ewing, LL, McDermott, IR, Reiner, WG, Robinson, CH, Scott, WW, Strandberg, JD, Talalay, and Walsh, PC : Comparison of spontaneous and experimentally induced canine prostatic hyperplasia. J Clin Invest $64: 842-849$, 1979.

3. Tunn, V, Serge, T, Schenck, B, and Neumann, F : Effects of cyproterone acetate on experimentally induced canine prostatic hyperplasia. A morphological and histochemical study. Urol Int 35 : 125-140, 1980.

4. Wilson, JD: The pathogenesis to benign prostatic hyperplasia. Am J Med 68: 745-756, 1980.

5. Bartsch, G, Bruengger, A Deklerk, DP, Coffey, DS and Rohr, HP : Light microscopic stereologic analysis of spontaneous and steroid-induced canine prostatic hyperplasia. J Urol 137 : 552-558, 1987.

6. Belis, JA, Adlestein, LB, and Tarry, WF : Influence of estradiol on accessory reproductive organs in the castrated male rats. J Androl 4 : 144-149, 1983.

7. Grayhack, JT, and Lebowitz, JA : Effect of prolactin on citric acid of lateral lobe prostate of SpragueDawley rat. Invest Urol 5 : 87-84, 1967.

8. Tisell, LE: The growth of the ventral prostate, the dorsolateral prostate, the coagulating glands and the seminal vesicles in castrated, adrenalectomized rats injected with oestradiol and/or cortisone. Acta Endocrinol (Copenh) 68 : 485-501, 1971.

9. $\mathrm{Yu}, \mathrm{M}$, Cates, I, Cates, I, Leaw, I and Ho, S : Heterogeneity of $\left[{ }^{3} \mathrm{H}\right]$-estradiol binding sites in the rat prostate. Properties and distribution of type I and type II sites. J Steroid Biochem 33 : 449-457, 1989.

10. Graham, RC, and Karnovsky, MJ : The early stage of absorption of injected horseradish peroxidase in the proximal tubules of mouse kidney. J Histochem Cytochem 14: 291-301, 1966.

11. McLean, IW, and Nakane, PK : Periodate-lysineparaformaldehyde fixative. A new fixative for immunoelectron microscopy. J Histochem Cytochem 22 : 1077-1083, 1974.

12. Nakane, PK : Recent progress in the peroxidaselabeled antibody method. Ann NY Acad Sci 234 : 203-211, 1975.

13. Zamboni, L, and DeMartino, C : Buffered picrinic acid-formaldehyde. A new rapid fixation for electron microscopy. J Cell Biol 35: 148A, 1967.

14. Mizokami, A Masai, M, Shimazaki, J, and Sugita, A : Production of polyclonal antibody against human androgen receptor and immunohistochemical study of human androgen receptor in prostatic tissues. Jpn J Urol 83 : 1801-1807, 1992 (In Japanese with English abstract).

15. Attia, MA, and Zayed, I : Thirteen-weeks subcutaneous treated with high dose of natural sex hormones in rats. With special reference to their effect on the pituitary-gonadal axis. Dtsch Tieraztt Wschr 96: 438-445, 1989.

16. Ciaccio, LA Joseph, AA, and Kinch, FA : Direct inhibition of testicular function in rats by oestradiol and progesterone. J Steroid Biochem 9: 12571259, 1978.

17. Tcholkian, RK, Chowdhury, M, and Chowdhury, AK : Recovery of testicular and pituitary functions in adult male rats after cessation of short and long term oestradiol treatment. Biol Reprod 19: 431438, 1978.

18. Ho, S, and $Y u, M$ : Selective increase in type II estrogen-binding sites in the dysplastic dorsolateral prostates of novel rats. Cancer Res 53 528-532, 1993.

19. Rohr, HP, Naef, HR, and Holliger, $O$ : The effect of oestrogen on stromal growth of the prostate. Urol Res 9: 201-207, 1981.

20. Murakoshi, M, Ikeda, K, and Watanabe, K: Immunocytochemical localization of glutathione-peroxidase (GSH-PO) in rat peritoneal macrophages. Acta Histochem Cytochem 19: 125-133, 1986.

21. Watanabe, $\mathrm{K}$, and Murakoshi, M : Lipid peroxida- 
tion and arachidonate cascade in macrophages with a special reference to the change in glutathione peroxidase, lipid peroxide scavenger. Tokai J Exp Clin Med 11(Suppl): 105-109, 1986.

22. Murakoshi, $M$, Tagawa, $M$, Inada, R, Suzuki, $M$, Mizokami, $\mathbf{A}$ and Watanabe, $\mathbf{K}$ : Inhibition of steroid-induced prostatic hyperplasia in rats by treatment with anti-androgen (TZP-4238). Endocrine J 40 : 479-488, 1993.
23. Murakoshi, M, Inada, R, Tagawa, M, Mizokami, A, and Suzuki, $M$ : Immunohistochemical evaluation of the effect of TZP-4238. Possible androgen receptor antagonist in rat prostate. Acta Histochem Cytochem 26 : 479-483, 1993.

24. Sar, M, Lubahn, DB, French, FS, and Wilson, EM : Immunohistochemical localization of the androgen receptor in rat and human tissues. Endocrinology 127 : $3180-3186,1990$. 